\title{
Estimating carbon dioxide fluxes from temperate mountain grasslands using broad-band vegetation indices
}

\author{
G. Wohlfahrt ${ }^{1}$, S. Pilloni ${ }^{1}$, L. Hörtnagl ${ }^{1}$, and A. Hammerle ${ }^{1,2}$ \\ ${ }^{1}$ Institute of Ecology, University of Innsbruck, Innsbruck, Austria \\ ${ }^{2}$ now at: ETH Zürich, Institute of Plant, Animal and Agroecosystem Sciences, Zürich, Switzerland
}

Received: 12 October 2009 - Published in Biogeosciences Discuss.: 27 November 2009

Revised: 8 February 2010 - Accepted: 12 February 2010 - Published: 17 February 2010

\begin{abstract}
The broad-band normalised difference vegetation index (NDVI) and the simple ratio (SR) were calculated from measurements of reflectance of photosynthetically active and short-wave radiation at two temperate mountain grasslands in Austria and related to the net ecosystem $\mathrm{CO}_{2}$ exchange (NEE) measured concurrently by means of the eddy covariance method. There was no significant statistical difference between the relationships of midday mean NEE with narrowand broad-band NDVI and SR, measured during and calculated for that same time window, respectively. The skill of broad-band NDVI and SR in predicting $\mathrm{CO}_{2}$ fluxes was higher for metrics dominated by gross photosynthesis and lowest for ecosystem respiration, with NEE in between. A method based on a simple light response model whose parameters were parameterised based on broad-band NDVI allowed to improve predictions of daily NEE and is suggested to hold promise for filling gaps in the NEE time series. Relationships of $\mathrm{CO}_{2}$ flux metrics with broad-band NDVI and SR however generally differed between the two studied grassland sites indicting an influence of additional factors not yet accounted for.
\end{abstract}

\section{Introduction}

Increases in atmospheric carbon dioxide $\left(\mathrm{CO}_{2}\right)$ since the industrial revolution are deemed responsible for about $60 \%$ of observed global warming (Solomon et al., 2007). Of the $7 \mathrm{Pg}$ carbon released on average each year to the atmosphere through the burning of fossil fuels, the terrestrial biosphere absorbs about one third (Canadell et al., 2007). Quantifying the spatial patterns of the net ecosystem exchange of $\mathrm{CO}_{2}$ (NEE) between land ecosystems and the atmosphere and pro-

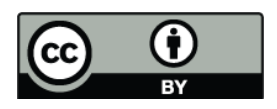

Correspondence to: G. Wohlfahrt (georg.wohlfahrt@uibk.ac.at) jecting how NEE will be affected by likely future climate and land use is thus a critical issue in environmental science (Steffen et al., 1998; Running et al., 1999; Baldocchi et al., 2001).

Remote sensing of radiation reflected from the Earth's surface from satellites allows monitoring the "status" of the entire planet Earth with reasonable spatial and temporal coverage (Malenovsky et al., 2009). Employing surface reflectance measurements for estimating NEE, while theoretically very appealing (Running et al., 1999), is however not straightforward, because NEE is the sum of two component fluxes of approximately equal magnitude: gross primary productivity (GPP) and ecosystem respiration (RECO). While a clear mechanistic link can be established between the reflectance (and absorption) of radiation of various wavelengths and GPP (Gamon et al., 1992), which is driven by the amount of absorbed quanta (Larcher, 2001), such a link is less obvious for RECO, which dominates NEE during nighttime (Grace et al., 2007; Malenovsky et al., 2009). For remote estimation of NEE, GPP is thus very often simulated based on surface reflectance and physiologi$\mathrm{cal} /$ biogeochemical modelling approaches are employed for deriving RECO (e.g. Turner et al., 2004; Olofsson et al., 2008). Validation of these models requires surface-based measurements of NEE (Running et al., 1999) - these are provided by the FLUXNET project (Baldocchi et al., 2001; Baldocchi, 2008) within which more than 500 stations around the globe are quantifying the NEE of a wide range of ecosystems by means of the eddy covariance (EC) method (Baldocchi et al., 1988; Aubinet et al., 2000).

A wide range of vegetation indices, calculated from reflectance in certain wavebands, has been used for inferring GPP. Very often these make use of the strong absorption by the photosystems (PS) I and II in the red (700 and $680 \mathrm{~nm}$ ) waveband, such as the well-known normalised difference vegetation index (NDVI; Rouse et al., 1974) or the enhanced vegetation index (Liu et al., 1995). The more sophisticated

Published by Copernicus Publications on behalf of the European Geosciences Union. 
photochemical reflectance index (Gamon et al., 1992) accounts for the fact that under certain stress conditions leaves divert excess radiative energy from PS II to the xantophyll cycle, resulting in a change in reflectance at the $531 \mathrm{~nm}$ wave band (Larcher, 2001). Recently, first attempts have been made to relate NEE to changes in fluorescence (Moya et al., 2004; Louis et al., 2005), that is the re-emission of radiative energy absorbed by PS II at wavebands of 690 and $740 \mathrm{~nm}$ (Larcher, 2001). All these vegetation indices, except for NDVI, require reflectance to be measured with a very narrow spectral resolution of $<10 \mathrm{~nm}$ (Grace et al., 2007). While many operational hyperspectral imaging spectroradiometers are able to provide this spectral resolution, few sites in the FLUXNET project provide appropriate ground truth data. As an alternative, first probably published by Huemmrich et al. (1999), reflectance in the broad bands of photosynthetically active (PAR; 400-700 $\mathrm{nm}$ ) and near-infrared (NIR; $700-3000 \mathrm{~nm}$ ) may be used to approximate the NDVI and other indices making use of the differential reflectance in these wave band regions. Broad-band NDVI has been successfully used to track phenology (Huemmrich et al., 1999; Wang et al., 2004; Richardson et al., 2007), predict the leaf area index (Wilson and Meyers, 2007; Rocha and Shaver, 2009) and GPP (Wang et al., 2004, 2009; Jenkins et al., 2007; Richardson et al., 2007). Given that most of the radiation measurements necessary to calculate broad-band vegetation indices, probably with the exception of reflected PAR, are made routinely at the majority of the existing flux towers the potential of broad-band vegetation indices has not yet been fully exploited and, at least to our knowledge, we are not aware of published studies which used broad-band vegetation indices to estimate NEE.

The overall objective of the present paper is thus to explore the potential of broad-band vegetation indices for estimating NEE and its component processes GPP and RECO. More specifically we aim at answering the following questions: (i) do broad-band vegetation indices exhibit a different relationship to $\mathrm{CO}_{2}$ fluxes as compared to narrow-band indices; (ii) how well do broad-band vegetation indices relate to NEE, GPP and RECO in comparison to commonly used predictors such as environmental variables or canopy characteristics; (iii) how general are the relationships between broad-band vegetation indices and the investigated $\mathrm{CO}_{2}$ flux metrics. To this end we use concurrent measurements of PAR and NIR reflectance, from which we calculate broad-band NDVI and simple ratio (SR), and NEE made at two temperate mountain grasslands in Austria.

\section{Material and methods}

\subsection{Site description}

The study sites are located on the flat bottoms of the Stubai and Inn valley in Western Austria close to the villages of
Neustift and Rotholz, respectively. A general characterisation of the study sites is given in Table 1. Neustift is cut three times a year with occasional light grazing in October, while Rotholz, due to the lower elevation and longer vegetation period, is cut three times a year with significant grazing in autumn (mid September to mid October). Both sites receive only (solid and liquid) organic manure, usually in late autumn. Plant species composition is fairly similar, most of the above-ground biomass being made up by around 10 dominant forb and grass species (Wohlfahrt et al., 2008). However, Rotholz is dominated by grasses (40-60\%), while grasses make up only $20-40 \%$ at Neustift.

\subsection{Net ecosystem $\mathrm{CO}_{2}$ exchange (NEE)}

Continuous eddy covariance (EC) measurements of the NEE have been made at Neustift and Rotholz since March 2001 and December 2007, respectively, and continue as of this writing. Within the frame of this study we used data from 2006-2008 (Neustift) and 2008 (Rotholz), as the corresponding multispectral reflectance (Neustift 2006) and radiation measurements (Neustift 2007-2008, Rotholz 2008) were available during these periods. $\mathrm{CO}_{2}$ fluxes were measured using the EC method (Baldocchi et al., 1988) following the procedures of the EUROFLUX project (Aubinet et al., 2000). For further details regarding instrumentation, data treatment and quality control we refer to our previous publications (Wohlfahrt et al., 2008; Haslwanter et al., 2009). Negative fluxes represent transport from the atmosphere towards the surface, positive ones the reverse.

Half-hourly NEE measurements were used to derive three groups of $\mathrm{CO}_{2}$ flux metrics:

1. For consistency with the time-window used for calculating broad-band vegetation indices (see below) we calculated midday mean NEE $\left(\mathrm{NEE}_{\mathrm{mdm}}\right)$ for the time period 10:00-14:00 Central European Time (CET);

2. Daily sums of NEE $\left(\mathrm{NEE}_{\mathrm{d}}\right)$ were derived by using a standardised approach for filling gaps (Falge et al., 2001; Moffat et al., 2007) as described in Wohlfahrt et al. (2008); ecosystem respiration (RECO) was calculated from nighttime NEE by extrapolation to daytime temperatures (Reichstein et al., 2005) and then integrated over each day $\left(\mathrm{RECO}_{\mathrm{d}}\right)$; gross primary productivity (GPP) was calculated as NEE-RECO and then integrated to daily values $\left(\mathrm{GPP}_{\mathrm{d}}\right)$; further details of this procedure are given in Wohlfahrt et al., 2008.

3. Light-response curve analysis is a powerful tool for characterising key ecosystem functional properties (Ruimy et al., 1995). In order to relate NEE to PAR we fitted (using the Levenberg-Marquard algorithm) the data (pooled into five-day blocks of data) to the following sigmoid model (Smith, 1937): 
Table 1. General characterisation of the two study sites.

\begin{tabular}{lll}
\hline & Neustift & Rotholz \\
\hline & & \\
Latitude & $47^{\circ} 07^{\prime} \mathrm{N}$ & $47^{\circ} 23^{\prime} \mathrm{N}$ \\
Longitude & $11^{\circ} 19^{\prime} \mathrm{E}$ & $11^{\circ} 48^{\prime} \mathrm{E}$ \\
Elevation (m a.s.l.) & 970 & 523 \\
Mean annual temperature $\left({ }^{\circ} \mathrm{C}\right)$ & 6.5 & 8.2 \\
Mean annual precipitation $(\mathrm{mm})$ & 852 & 1151 \\
Vegetation type & Pastinaco-Arrhenatheretum & Lolietum multiflorae \\
Soil type (FAO classification) & Gleyic Fluvisol & Gleyic Fluvisol \\
\hline
\end{tabular}

$\mathrm{NEE}=\frac{\alpha Q_{\mathrm{PAR}} F_{\mathrm{sat}}}{\sqrt{F_{\mathrm{sat}}^{2}+\left(\alpha Q_{\mathrm{PAR}}\right)^{2}}}+R_{\mathrm{eco}}$

Here $\alpha$ represents the apparent quantum yield $\left(\right.$ mol CO$_{2}$ mol photons $\left.{ }^{-1}\right), \quad F_{\text {sat }}$ the asymptotic value of the gross primary production (GPP) at high irradiance $\left(\mu \mathrm{mol} \mathrm{CO} \mathrm{m}^{-2} \mathrm{~s}^{-1}\right.$; referred to as $\mathrm{GPP}_{\max }$ in the following), $Q_{\text {PAR }}$ the PAR ( $\mu$ mol photons $\mathrm{m}^{-2} \mathrm{~s}^{-1}$ ) and $R_{\text {eco }}$ the ecosystem respiration $\left(\mu \mathrm{mol} \mathrm{CO} \mathrm{CO}^{-2} \mathrm{~s}^{-1}\right.$ ). Equation (1) represents an unbiased approximation to the light response of a wide range of ecosystems and is much better suited than the often used rectangular and non-rectangular hyperbolic models (A. Moffat, personal communication, 2009).

\subsection{Multispectral reflectance and narrow-band vegetation indices}

Multispectral reflectance was measured with a portable spectroradiometer (FieldSpec Handheld, ASD Inc., Boulder, CO, USA) with a $3 \mathrm{~nm}$ spectral resolution (325-1075 $\mathrm{nm}$ range). Measurements of nadir vegetation radiance and the zenith sky irradiance, from which reflectance was calculated, were made with a cosine diffuser foreoptic $\left(170^{\circ}\right.$ field of view) at the same representative vegetation spot around noon on 20 clear days between April and October 2006. To this end the spectroradiometer was mounted $1.5 \mathrm{~m}$ above ground on a horizontally protruding rotating arm on a tripod allowing alternating downward and upward measurements without disturbing the vegetation and interfering with the reflectance measurement (Gianelle et al., 2009).

For each measurement date the normalised difference vegetation index (NDVI) and the simple ratio (SR) were calculated based on five replicate measurements (coefficients of variation generally $<5 \%$ ) of the reflectance in the NIR (770$780 \mathrm{~nm})$ and red $(670-680 \mathrm{~nm})$ wavebands $\left(r_{\text {nir }}, r_{\text {red }}\right)$ :

$\mathrm{NDVI}=\frac{\left(r_{\text {nir }}-r_{\text {red }}\right)}{\left(r_{\text {nir }}+r_{\text {red }}\right)}$

$\mathrm{SR}=\frac{r_{\text {nir }}}{r_{\text {red }}}$

\subsection{Radiation measurements and broad-band vegetation indices}

Incoming total and diffuse photosynthetically active radiation (PAR) were measured by photodiodes (BF2H, Delta-T Devices Ltd, Cambridge, UK) mounted at $2 \mathrm{~m}$ above ground. PAR incident on the ground surface $\left(\mathrm{PAR}_{\mathrm{soil}}\right)$ and reflected PAR $\left(\right.$ PAR $\left._{\text {refl }}\right)$ were measured by a line quantum sensor (10 individual sensors providing an averaged output) and a single quantum sensor (LQS7010_Sun and QSO_Sun, respectively, Apogee Instruments, Logan, USA). The line quantum sensor measuring PAR $_{\text {soil }}$ was mounted in a U-shaped aluminium profile, which was placed about $0.01 \mathrm{~m}$ below the soil surface in order to measure the PAR incident on the soil surface. The pyranometers of the CNR-1 net radiometer (CNR-1, Kipp and Zonen, Delft, The Netherlands) were used for measuring the up- and down-welling global radiation $\left(R_{\mathrm{g}}, 305\right.$ to $2800 \mathrm{~nm}$ ). All radiation sensors were inter-calibrated prior to the experiment in order to avoid systematic biases.

PAR photon flux densities ( $\mu$ mol photons $\mathrm{m}^{-2} \mathrm{~s}^{-1}$ ) were converted to energy units $\left(\mathrm{J} \mathrm{m}^{-2} \mathrm{~s}^{-1}\right)$ using $4.55 \mu \mathrm{mol} \mathrm{J}^{-1}$ (Goudriaan and Van Laar, 1994) for both incident and reflected PAR, neglecting any spectral differences between the two. Ignoring any radiation in the $305-400 \mathrm{~nm}$ range, near infrared radiation (NIR) was then calculated from $R_{\mathrm{g}}$ by subtracting the PAR component:

$\mathrm{NIR}_{\mathrm{in}}=R_{\mathrm{g}_{\mathrm{in}}}-\mathrm{PAR}_{\mathrm{in}}$

$\mathrm{NIR}_{\text {refl }}=R_{\mathrm{g}_{\text {refl }}}-\mathrm{PAR}_{\text {refl }}$

Broad-band NDVI and SR were then calculated by replacing $r_{\text {nir }}$ and $r_{\text {red }}$ in Eqs. (2) and (3) with NIR refl $/ \mathrm{NIR}_{\text {in }}$ and $\mathrm{PAR}_{\mathrm{refl}} / \mathrm{PAR}_{\mathrm{in}}$, respectively. In order to minimise the effect of daily and seasonal changes in the sun's elevation, the broad-band NDVI and SR were averaged around midday between 10:00-14:00 CET. In addition, data were excluded when the site was covered by snow or when it had rained four hours prior or during the midday averaging period.

The calculation of broad-band vegetation indices as described above involves some simplifications/compromises - 

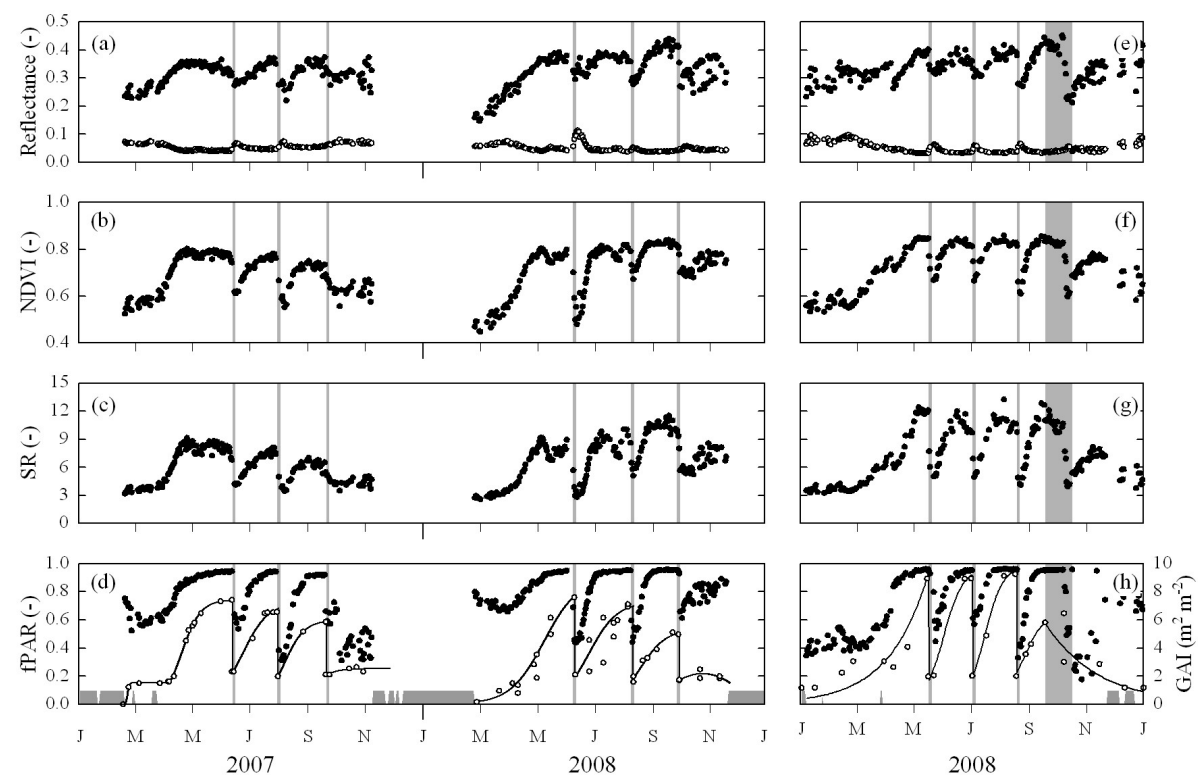

Fig. 1. Seasonal variation of (a, e) reflectance in photosynthetically active (PAR, open symbols) and near-infrared radiation (NIR, closed symbols), (b, f) normalized difference vegetation index (NDVI), (c, g) simple ratio (SR), and (d, h) fraction of absorbed PAR (fPAR) and measured (symbols) and simulated (lines) GAI. Snow cover periods (d, h) and cutting/grazing events are indicated by grey horizontal and vertical bars, respectively.

in particular neglecting spectral differences in up- and downwelling PAR, the conversion of PAR from photon to energy flux density and lumping the $305-400 \mathrm{~nm}$ waveband to the NIR component has the potential to systematically bias results. Because the precise magnitude of these uncertainties is hard to quantify and because we also wanted to account for additional potential sources of uncertainty (e.g. due to shifts in sensor sensitivity with time) we have conducted an uncertainty analysis by arbitrarily assuming a $20 \%$ uncertainty in the NIR and PAR reflectance, either separately or in combination with uncertainties of opposing magnitude. To this end reflectance values typical for small $\left(r_{\mathrm{NIR}}: 0.21, r_{\mathrm{PAR}}: 0.08\right)$ and large $\left(r_{\mathrm{NIR}}: 0.45, r_{\mathrm{PAR}}: 0.04\right)$ amounts of above-ground phytomass (Fig. 1) were used. A $20 \%$ uncertainty in either the NIR or PAR reflectance resulted in uncertainties of up to 20 and 25\% for NDVI and SR, respectively. For NDVI this uncertainty was smaller for large NDVI values (only $4 \%$ ). Uncertainties up to 38 and 50\%, for NDVI and SR respectively, were observed when uncertainties in NIR or PAR reflectance were assumed to occur jointly and in opposite directions.

The fraction of absorbed photosynthetically active radiation (fPAR) was calculated by assuming a soil reflectance of $15 \%$ (Goudriaan, 1977) and again averaged around midday between 10:00-14:00 CET.

$\mathrm{fPAR}=\frac{\mathrm{PAR}_{\text {in }}-\mathrm{PAR}_{\text {refl }}-0.85 \mathrm{PAR}_{\text {soil }}}{\mathrm{PAR}_{\text {in }}}$

The amount of absorbed PAR (aPAR) was calculated from fPAR by multiplication with incident PAR.

\subsection{Ancillary data}

Further supporting meteorological measurements included air temperature (TA) and humidity (RH) at $2 \mathrm{~m}$ above ground and soil temperature (TS) at $0.05 \mathrm{~m}$ depth, measured by the means of a combined temperature/humidity sensor (RFT-2, UMS, Munich, Germany) and an averaging soil thermocouple (TCAV, Campbell Scientific, Logan, UT, USA), respectively. Further, soil water content (SWC; at $0.1 \mathrm{~m}$ soil depth) (ML2x, Delta-T Devices, Cambridge, UK) and precipitation (Precip) (52202, R. M. Young, Traverse City, MI, USA) were measured.

Green, photosynthetically active stems make up a considerable fraction of the above-ground biomass (Wohlfahrt et al., 2001). Therefore we use the green area index (GAI, $\mathrm{m}^{2} \mathrm{~m}^{-2}$ ), which comprises both leaves and green stems, instead of the commonly used leaf area index for quantifying the amount of photosynthetically active plant surface. The GAI was assessed (i) in a destructive fashion by clipping of square plots of $0.09 \mathrm{~m}^{2}$ (3-5 replicates) and subsequent plant area determination (Li-3100, Li-Cor, Lincoln, NE, USA) and (ii) from measurements of canopy height which was related to destructively measured GAI. Continuous time series of the GAI were derived by fitting appropriate empirical functions, separately for each growing phase, to measured data. 


\section{Results}

Seasonal canopy development, governed by the cuts and the subsequent plant regrowth, of the investigated grasslands led to characteristic patterns in reflectance and vegetation indices (Fig. 1). Representative examples of corresponding changes in multispectral reflectance are pictured in Fig. 2, which shows that when little vegetation cover was present a comparably larger fraction of the radiation in the PAR was reflected, while reflectance was smaller in the NIR resulting in low narrow-band NDVI and SR values (compare to Eqs. 2 and 3). As the amount of above-ground plant matter increased, reflectance decreased rapidly in the PAR and increased in the NIR (Fig. 2), causing narrow-band NDVI and SR to increase.

Broad-band reflectance and reflectance indices showed a qualitatively similar behaviour: Mean midday NIR reflectance increased asymptotically with increasing GAI and fPAR towards the cutting events, ranging between 0.150.40 and $0.20-0.45$ at Neustift and Rotholz, respectively (Fig. 1). In contrast, PAR reflectance decreased asymptotically from around 0.10 down to 0.04 during the same periods (Fig. 1). The cutting events reduced NIR and increased PAR reflectance, setting values back close to springtime levels. Mirroring the trends in NIR and PAR reflectance, both the NDVI and SR increased asymptotically during the various growing phases. NDVI started at approximately 0.45 and levelled off at around 0.85, SR increased from values around 2 up to 13 (Fig. 1). Note that reflectance values and vegetation indices during the phase of intensive grazing at Rotholz remained elevated because we failed to adequately simulate grazing below the (fenced) radiation sensors (Fig. 1). In an attempt to rectify this situation we cut the grass down to the actual grazing level in early October, resulting in an immediate decrease in reflectance values and vegetation indices (Fig. 1). Because of the mismatch with NEE, representative of the grazed area, data after the beginning of grazing were excluded from the following analysis.

Midday means of NEE (averaged between 10:0014:00 CET) showed a sharp increase in carbon uptake in early spring and after the cutting events, which levelled off at about $-26 \mu \mathrm{mol} \mathrm{CO} \mathrm{Cm}^{-2} \mathrm{~s}^{-1}$ at both sites (Fig. 3). The cutting events strongly reduced midday mean NEE for several days or even caused it to change sign (maximum loss around $12 \mu \mathrm{mol} \mathrm{CO}_{2} \mathrm{~m}^{-2} \mathrm{~s}^{-1}$ ). After the third cut both sites again turned into sinks over the midday hours, but did not reach $\mathrm{CO}_{2}$ uptake values comparable to those in the previous phases (Fig. 3). These were further reduced at Rotholz during a period of intensive grazing. Qualitatively similar patterns emerged from the analysis of daily NEE (Fig. 3), except for that maximum daily NEE tended to decrease over the course of the vegetation period at Rotholz. This was caused by RECO progressively increasing until the beginning of September, while daily GPP largely followed the seasonal course of the GAI (Fig. 1).

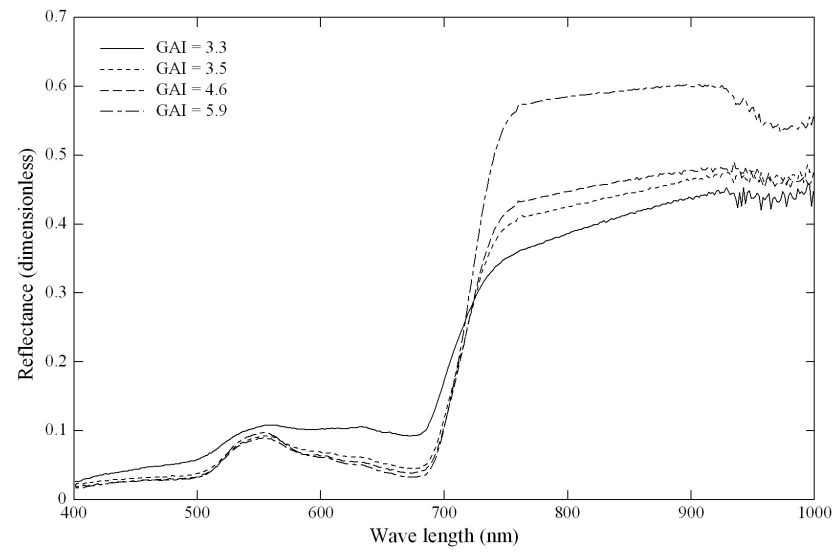

Fig. 2. Representative examples of multispectral reflectance for a range of GAI (green area index) values. Data have been measured at the study site Neustift during June-July 2006. The corresponding NDVI(SR) values are (in order of ascending GAI): 0.56(3.52), 0.67(5.13), 0.70(5.76), 0.76(7.31).

As shown in Fig. 4, the relationships between narrow- and broad-band NDVI and SR, which were measured and averaged around noon respectively, and midday mean NEE were very similar (data available only at Neustift). This is confirmed by a comparison of the slopes and $y$-intercepts of linear regressions between NDVI and SR against $\mathrm{NEE}_{\mathrm{mdm}}$, which were statistically indistinguishable $(p>0.63)$ between both methods.

A linear regression analysis shows that broad-band vegetation indices (i.e. NDVI and/or SR) averaged over midday hours explained most of the variability in NEE averaged over that same period $\left(\mathrm{NEE}_{\mathrm{mdm}}\right)$ and in daily NEE, followed by fPAR and aPAR, GAI, and finally by the investigated environmental parameters (Table 2). In contrast, while broadband NDVI and SR were still excellent predictors for daily GPP (the best for Rotholz), the difference to the environmental variables was lower. This was even more so the case for daily RECO, where most of the variability was explained by air and soil temperatures, and broad-band NDVI and SR explained hardly as much or even less of the variability as compared to day length (Table 2). A similar result was obtained for the ecosystem respiration parameter in the light response curve model ( $R_{\text {eco }}$, Eq. 1). The other parameters of Eq. (1), the apparent quantum yield $(\alpha)$ and the GPP at saturating light intensity $\left(\mathrm{GPP}_{\max }\right)$ were generally well explained by the broad-band vegetation indices (Table 1). The slopes and $y$-intercepts of these linear relationships (Figs. 4, 5 and 6) were significantly different between Neustift und Rotholz for all dependent variables in Table 2 except for $\mathrm{GPP}_{\mathrm{d}}$ (slope), $\mathrm{NEE}_{\mathrm{mdm}}$ ( $y$-intercept), $\alpha$ and Reco (slope and $y$-intercept). A step-wise multiple regression (data not shown) yielded hardly any improvement for ecosystem respiration $\left(\mathrm{RECO}_{\mathrm{d}}\right.$ and $R_{\text {eco }}$ ), while the largest improvement in explained variance (up to $33 \%$ ) was observed for daily NEE. 

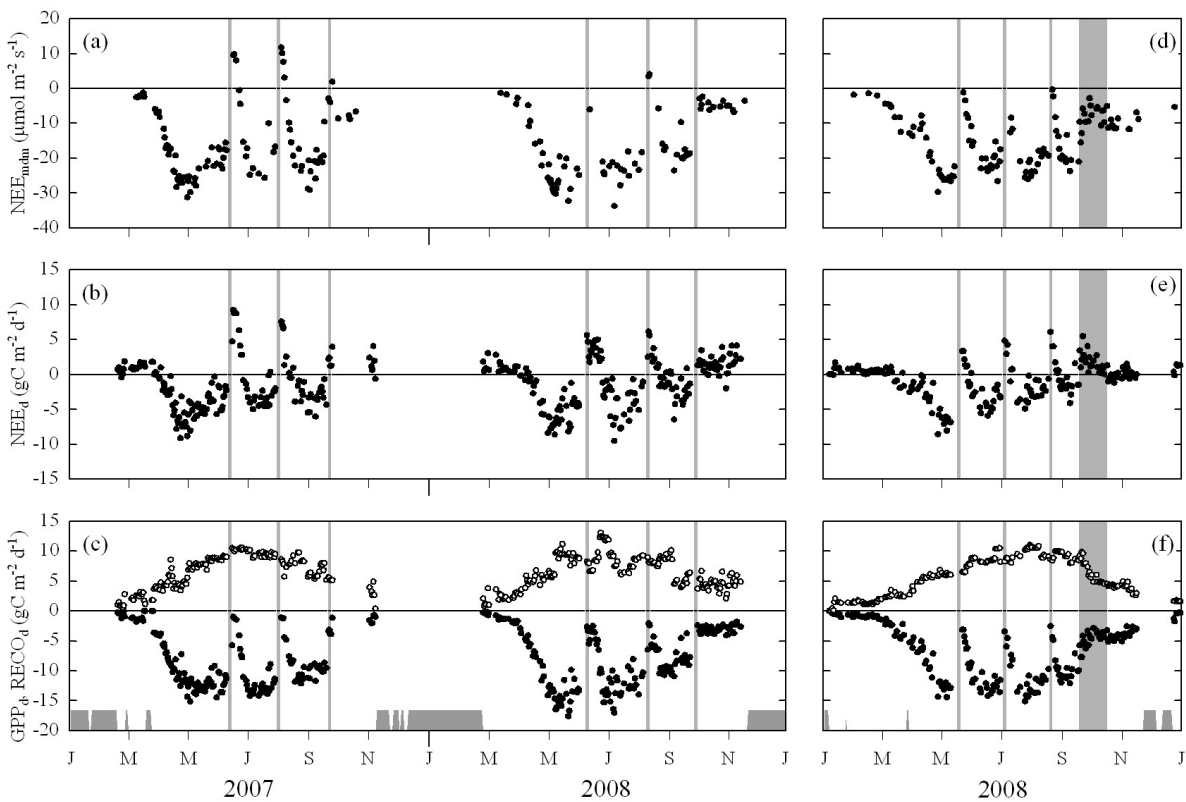

Fig. 3. Seasonal variation of (a, d) midday mean net ecosystem $\mathrm{CO}_{2}$ exchange $\left(\mathrm{NEE}_{\mathrm{mdm}}\right)$, (b, e) daily net ecosystem $\mathrm{CO}_{2}$ exchange $\left(\mathrm{NEE}_{\mathrm{d}}\right)$, and (c, f) daily gross primary productivity $\left(\mathrm{GPP}_{\mathrm{d}}\right.$, closed symbols) and daily ecosystem respiration (RECO $\mathrm{d}_{\mathrm{d}}$, open symbols). Snow cover periods $(\mathrm{c}, \mathrm{f})$ and cutting/grazing events are indicated by grey horizontal and vertical bars, respectively.

Table 2. Results (Pearson correlation coefficients) of linear regression analysis.

\begin{tabular}{|c|c|c|c|c|c|c|c|c|c|c|c|c|c|c|}
\hline & \multicolumn{7}{|c|}{ Neustift } & \multicolumn{7}{|c|}{ Rotholz } \\
\hline & $\mathrm{NEE}_{\mathrm{mdm}}$ & $\mathrm{NEE}_{\mathrm{d}}$ & $\mathrm{GPP}_{\mathrm{d}}$ & $\mathrm{RECO}_{\mathrm{d}}$ & $\alpha$ & $\mathrm{GPP}_{\max }$ & $R_{\text {eco }}$ & $\mathrm{NEE}_{\mathrm{mdm}}$ & $\mathrm{NEE}_{\mathrm{d}}$ & $\mathrm{GPP}_{\mathrm{d}}$ & $\mathrm{RECO}_{\mathrm{d}}$ & $\alpha$ & $\mathrm{GPP}_{\max }$ & $R_{\text {eco }}$ \\
\hline NDVI & -0.79 & -0.66 & -0.78 & 0.51 & 0.68 & -0.79 & 0.41 & -0.90 & -0.68 & -0.95 & 0.83 & 0.77 & -0.96 & 0.81 \\
\hline SR & -0.76 & -0.69 & -0.77 & 0.45 & 0.64 & -0.78 & 0.36 & -0.90 & -0.72 & -0.93 & 0.76 & 0.70 & -0.96 & 0.75 \\
\hline GAI & -0.66 & -0.63 & -0.84 & 0.65 & 0.64 & -0.83 & 0.60 & -0.77 & -0.66 & -0.91 & 0.79 & 0.70 & -0.90 & 0.77 \\
\hline fPAR & -0.79 & -0.72 & -0.72 & 0.34 & 0.57 & -0.70 & 0.21 & -0.88 & -0.70 & -0.91 & 0.75 & 0.69 & -0.95 & 0.73 \\
\hline aPAR & -0.67 & -0.68 & -0.79 & 0.50 & 0.34 & -0.86 & 0.61 & -0.84 & -0.70 & -0.91 & 0.75 & 0.61 & -0.95 & 0.79 \\
\hline PAR & -0.31 & -0.44 & -0.60 & 0.48 & 0.13 & -0.68 & 0.69 & -0.57 & -0.50 & -0.78 & 0.72 & 0.59 & -0.87 & 0.84 \\
\hline $\mathrm{TA}$ & -0.22 & -0.21 & -0.63 & 0.82 & 0.49 & -0.64 & 0.89 & -0.35 & -0.24 & -0.77 & 0.92 & 0.75 & -0.76 & 0.98 \\
\hline $\mathrm{TS}$ & -0.18 & -0.18 & -0.64 & 0.87 & 0.51 & -0.59 & 0.87 & -0.47 & -0.27 & -0.82 & 0.97 & 0.80 & -0.78 & 0.98 \\
\hline VPD & -0.20 & -0.30 & -0.50 & 0.49 & 0.25 & -0.65 & 0.70 & -0.26 & -0.26 & -0.57 & 0.62 & 0.49 & -0.69 & 0.81 \\
\hline SWC & 0.32 & 0.31 & 0.49 & -0.45 & -0.11 & 0.38 & -0.31 & -0.15 & -0.18 & -0.37 & 0.39 & 0.36 & -0.22 & 0.22 \\
\hline DL & n.a. & -0.35 & -0.70 & 0.77 & n.a. & n.a. & n.a. & n.a. & -0.44 & -0.80 & 0.81 & n.a. & n.a. & n.a. \\
\hline$n$ & 167 & 346 & 346 & 346 & 89 & 89 & 89 & 86 & 149 & 149 & 149 & 43 & 43 & 43 \\
\hline
\end{tabular}

Bold numbers indicate that regressions are statistically significant $(p<0.05) ; \mathrm{NEE}_{\mathrm{mdm}} \ldots$ midday mean net ecosystem $\mathrm{CO}_{2}$ exchange, $\mathrm{NEE}_{\mathrm{d}} \ldots$ daily net ecosystem $\mathrm{CO}_{2}$ exchange, $\mathrm{GPP}_{\mathrm{d}} \ldots$ daily gross primary productivity, $\mathrm{RECO}_{\mathrm{d}} \ldots$ daily ecosystem respiration, $\alpha$ ... apparent quantum yield, $\mathrm{GPP}_{\max } \ldots$ gross primary productivity at saturating light intensity, $R_{\mathrm{eco}} \ldots$ ecosystem respiration, NDVI ... broad-band normalised difference vegetation index, SR ... broad-band simple ratio, GAI ... green area index, fPAR ... fraction of absorbed photosynthetically active radiation, aPAR ... absorbed photosynthetically active radiation, PAR ... incident photosynthetically active radiation, TA ... air temperature, TS ... soil temperature, VPD ... vapour pressure deficit, SWC ... soil water content, DL ... day length, $n \ldots$ number of samples.

Because broad-band vegetation indices explained only between $44-52 \%$ of the variability in daily NEE at both sites, Eq. (1) and the best-fitting relationships of the parameters of Eq. (1) in Table 2, which are shown in Fig. 6, were used to predict daily NEE. Daily NEE predicted with this model explained 65 and $80 \%$ of the variability in measured daily
NEE for Neustift and Rotholz, respectively (Fig. 6; compare to results shown in Table 2). The slopes and $y$-intercepts of linear regressions between simulated and measured daily NEE were not significantly different $(p<0.05)$ from unity and zero, respectively, for Rotholz, but for Neustift. 


\section{Discussion}

Concurrent measurements of PAR and NIR reflectance, from which broad-band NDVI and SR were calculated, and NEE were made at two temperate mountain grasslands in Austria. The objective of this study was to explore the potential of broad-band NDVI and SR for predicting NEE and its two component processes, GPP and RECO. Our main findings were: i) there was no significant statistical difference between the relationship of midday mean NEE to narrow- and broad-band NDVI and SR, measured during and calculated for that same time window, respectively; ii) the skill of broadband NDVI and SR in predicting $\mathrm{CO}_{2}$ fluxes was higher for metrics dominated by gross photosynthesis and lowest for ecosystem respiration, with NEE in between; iii) relationships of $\mathrm{CO}_{2}$ flux metrics with broad-band NDVI and SR generally differed between the two studied grassland sites.

The utility of broad-band as opposed to narrow-band vegetation indices depends on how well the former compare with the latter (and how sensitive the process to be inferred is to these vegetation indices). While several studies have compared broad-band vegetation indices against their narrow-band counterparts based on satellite data (Wang et al., 2004; Jenkins et al., 2007; Rocha and Shaver, 2009), there are actually only two studies we are aware of that compared in-situ (i.e. without the confounding effects of atmospheric corrections) measured broad- with narrow-band vegetation indices: Both Huemmrich et al. (1999) and Rocha and Shaver (2009) reported acceptable correspondence between broad- and narrow-band NDVI measured using radiation sensors and a spectroradiometer above several boreal forest ecosystems and along a tundra burn severity gradient in Alaska, respectively. Our study, while not able to directly compare broad- and narrow-band vegetation indices as these have been measured during different years, lends further support to the utility of broad-band vegetation indices as we were able to show that the relationship to midday mean NEE did not significantly differ from the one determined from multispectral (narrow-band) data (Fig. 4). Reflectance in the broad spectral regions of PAR and NIR are thus obviously able to capture many of the characteristic features of narrowband vegetation indices despite integrating over much larger waveband region (Huemmrich et al., 2009).

NDVI and SR have been successfully related to gross photosynthesis (e.g. Gianelle et al., 2009) because they mathematically contrast the strong absorption by the photosystems I and II in the red which drives photosynthesis (Larcher, 2001), with the large reflectance in the NIR, which is largely the result of photon scattering within the leaf tissue at the aircell interfaces of the mesophyll (Asner, 1998). It thus comes as no huge surprise that gross photosynthesis at saturating light intensity $\left(\mathrm{GPP}_{\max }\right)$ and daily GPP, but also midday mean NEE, which bears a considerable "assimilatory signature", were highly correlated with broad-band NDVI and/or SR (Table 2). Conversely, vegetation indices were poor pre-
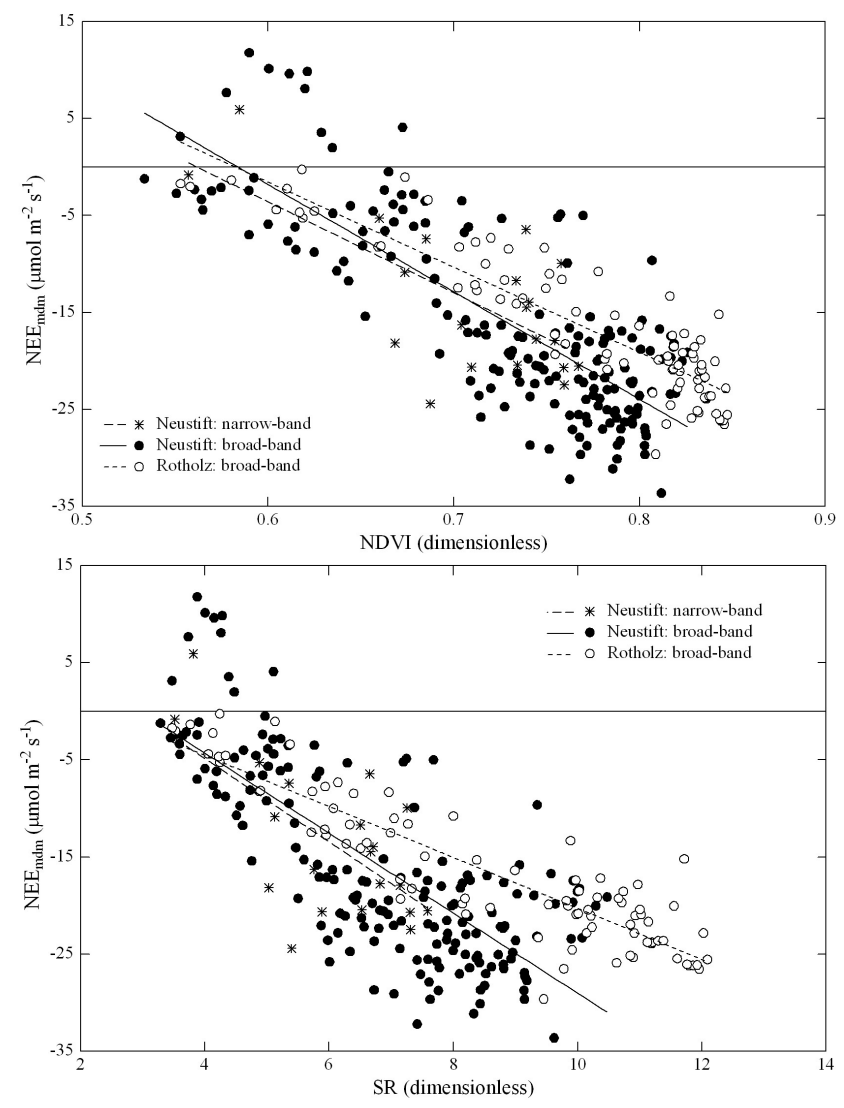

Fig. 4. Relationship between normalized difference vegetation index (NDVI, upper panel) and simple ratio (SR, lower panel) and midday mean net ecosystem $\mathrm{CO}_{2}$ exchange $\left(\mathrm{NEE}_{\mathrm{mdm}}\right)$.

dictors of ecosystem respiration, because reflectance is not directly related to the various, both auto- and heterotrophic, component processes which contribute to ecosystem respiration (Grace et al., 2007). Seemingly, the now well established link between ecosystem respiration and photosynthesis via the supply of fresh substrate for assimilation (e.g. Högberg et al., 2001; Bahn et al., 2009) was not exerting as strong a control as compared to temperature (Table 2), which affects the speed of metabolic reactions (Davidson and Janssens, 2006). Soil water content, affecting the accessibility of organic substrates in the soil (Davidson and Janssens, 2006), did not play a major role at our sites, in accordance with the findings of Wohlfahrt et al. (2008) for Neustift.

For deriving and monitoring yearly and longer-term NEE by remote sensing it would be desirable to predict daily NEE (Running et al., 1999). Very often, however, vegetation indices are poorly related to daily NEE (44-52\% explained variance in the present case; Table 2), which reflects the good and poor correlations with GPP and RECO, respectively (Olofsson et al., 2008). Daily NEE, furthermore, suffers from an unwanted influence of the length of the daylight period, although it was not as large as for daily GPP 

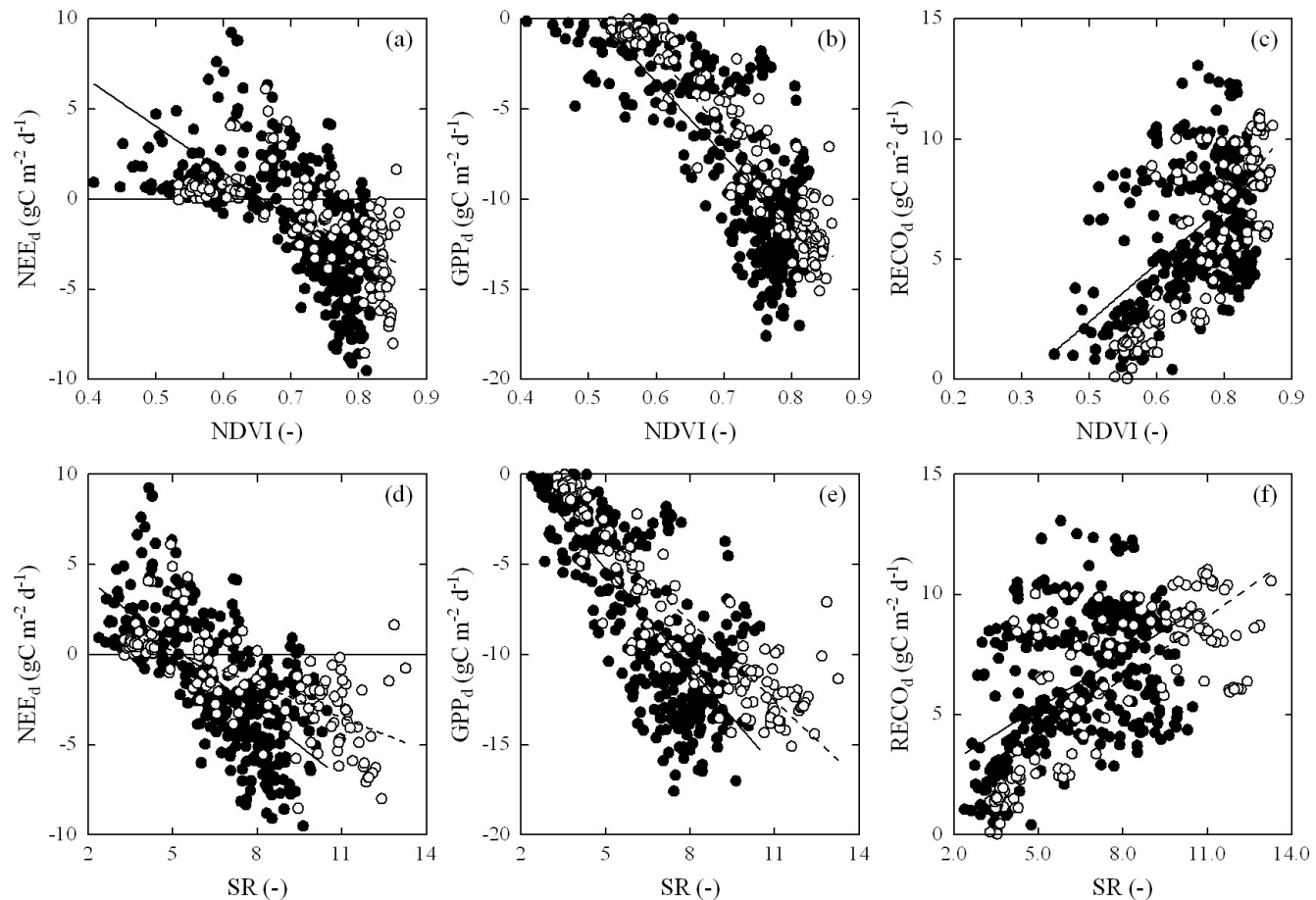

Fig. 5. Relationship between (a-c) normalized difference vegetation index (NDVI) and (d-f) simple ratio (SR, lower panel) and (a, d) daily net ecosystem $\mathrm{CO}_{2}$ exchange $\left(\mathrm{NEE}_{\mathrm{d}}\right)$, (b, e) daily gross primary productivity $\left(\mathrm{GPP}_{\mathrm{d}}\right)$, and $(\mathrm{c}, \mathrm{f})$ daily ecosystem respiration $\left(\mathrm{RECO}_{\mathrm{d}}\right)$. Closed and open symbols represent the study sites Neustift and Rotholz, respectively.
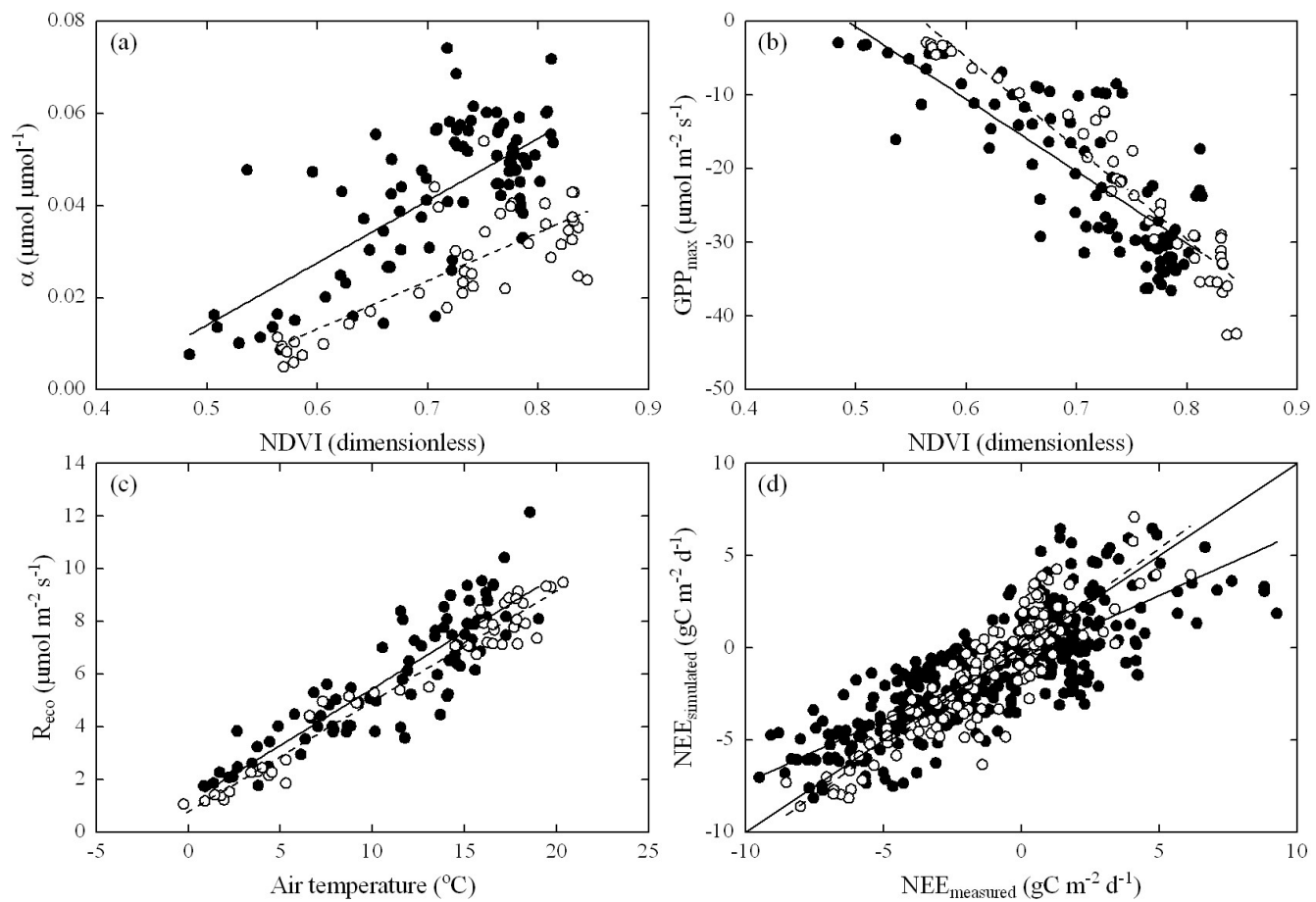

Fig. 6. Relationship between (a, b) normalized difference vegetation index (NDVI) and the apparent quantum yield ( $\alpha$ ) and gross primary productivity under saturating light conditions $\left(\mathrm{GPP}_{\max }\right)$, (c) air temperature and ecosystem respiration $\left(R_{\mathrm{eco}}\right)$, and (d) correspondence between the measured and simulated (using Eq. 1 and relationships shown in panels a-c) daily net ecosystem $\mathrm{CO}_{2}$ exchange. 

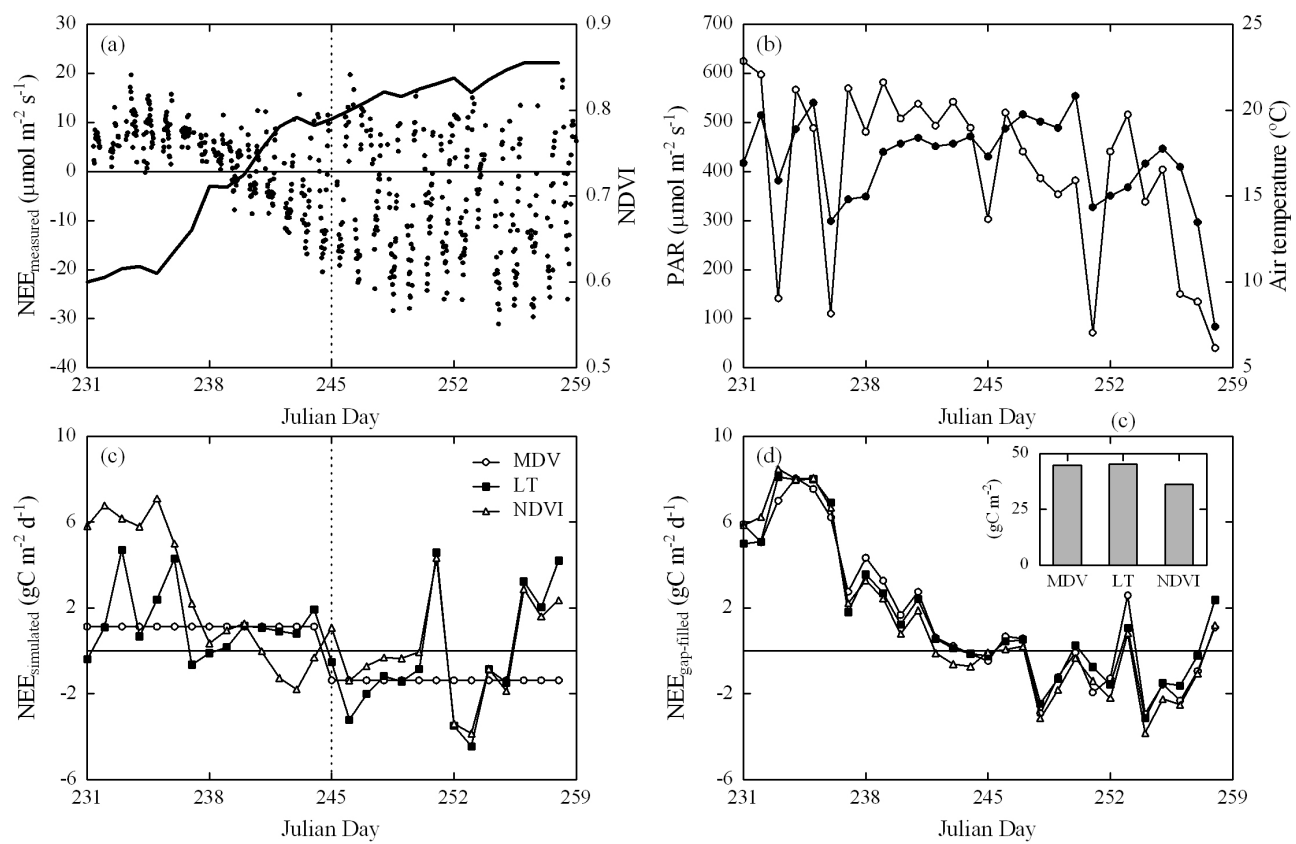

Fig. 7. Example illustrating the potential of Eq. (1) and the relationships shown in Fig. 6 for gap-filling of NEE time series. Data are from 2008 for the study site Rotholz and show (a) the half-hourly measured NEE (symbols) and the midday average broad-band NDVI (solid line), (b) daily average PAR (open symbols) and air temperature (closed symbols), (c) daily NEE simulated based on various gap-filling approaches and (d) daily and 28-day-integrated (inset) NEE gap-filled with various approaches. MDV refers to the mean diurnal variation method and LT to light- and temperature-dependent regression models (Falge et al., 2001). The vertical dotted lines in panels (a) and (c) indicate the two-week blocks of data used for the MDV and LT approaches. See text for further details.

and RECO, where the length of the daylight period already explained $>50 \%$ of the variability in data (Table 2 ). The correlation with daily NEE, as with all daily metrics, may also be lower because vegetation indices calculated from midday mean reflectance values may not well reflect $\mathrm{CO}_{2}$ exchange during other times of the day (Sims et al., 2005). Accordingly, daily NEE was the metric which profited most from including additional predictors in a multiple linear regression $\left(r^{2}\right.$ increased by up to $\left.33 \%\right)$. Besides this statistical approach, predictions of daily NEE could also be improved, resulting in $64-80 \%$ explained variance, by using a more mechanistic light response curve model (Eq. 1) with its parameters modelled (Fig. 6) as a function of broad-band NDVI $\left(\alpha, \mathrm{GPP}_{\max }\right)$ and air temperature $\left(R_{\mathrm{eco}}\right)$. However, in order to drive this model, sub-daily (i.e. half-hourly) PAR is required as input, which may limit its applicability. In fact, this approach may hold more promise for reducing the uncertainty of gap-filled data products (Falge et al., 2001; Moffat et al., 2007). In particular for long data gaps, which represent a large source of uncertainty (Richardson and Hollinger, 2007), or when rapid changes in ecosystem $\mathrm{CO}_{2}$ exchange occur, such as with the investigated grasslands (Wohlfahrt et al., 2008) or during leaf-out of deciduous forests (Richardson et al., 2007), broad-band vegetation indices may provide a good proxy for changes in ecosystem physiological activity (Wang et al., 2009) and could be assimilated into the gap- filling procedure. An example for this is given in Fig. 7, which shows (using data from Rotholz) differences in gapfilled NEE for a four-week period following the third cut in 2008 between the proposed approach (i.e. Eq. 1 and the relationships shown in Fig. 6) and the mean diurnal variation (MDV) and combined light/temperature regression (LT) approach (Falge et al., 2001). For the latter two approaches, a frequently used fixed two-week time window was used. As opposed to the NDVI-based approach, which used daily midday average NDVI as input, this caused an overestimation and underestimation of $\mathrm{CO}_{2}$ uptake at the beginning and end of the two-week blocks of data, respectively (Fig. 7c). The consequences of these differences for gap-filling depend on the number, length and distribution of gaps. In the present example, with around $40 \%$ gaps predominately during nighttime, NEE was similar for the MDV and LT approach and 25\% lower for the NDVI-based approach (Fig. 7d).

The relationships between the various $\mathrm{CO}_{2}$ flux metrics and broad-band NDVI and SR were generally sitespecific (Figs. 4, 5 and 6), making the application of these relationships to other grassland ecosystems problematic. This is not uncommon for purely statistical relationships (e.g. McMichael et al., 1999) and very much likely results from unaccounted differences between the two sites in terms of ecosystem structure, e.g. species composition in conjunction with species-specific differences in leaf optical 
properties or leaf angles, and function, e.g. the relationship between leaf biophysical/biochemical properties and photosynthesis (Asner, 1998). Because of the relatively large amounts of above-ground phytomass we do not believe that the broad-band Enhanced Vegetation Index, recently put forward by Rocha and Shaver (2009) because of its ability to account for differences in soil background reflectance, would be able to remedy these differences. Rather, a more mechanistic treatment of the relationships between reflectance in various wavebands and NEE and its component processes, as done in some process-oriented models (e.g. Van der Tol et al., 2009), will be required to this end.

Given that most of the radiation measurements necessary to calculate broad-band vegetation indices, probably with the exception of reflected PAR, are made routinely at the majority of the existing FLUXNET sites it would require relatively little extra effort to extend these measurements to a larger number of sites. As our uncertainty analysis (see Sect. 2.4) showed that both vegetation indices, but in particular SR, were very sensitive to errors in PAR and NIR reflectance (in particular if both change in opposing directions), any implementation of such measurements should be accompanied by an appropriate (network-wide) quality control protocol.

Acknowledgements. This study was financially supported by the Austrian National Science Fund under contracts P17560 and P19849 and the Tyrolean Science Fund under contracts Uni-404/33 and Uni-404/486. A. Hammerle acknowledges financial support through a DOC fellowship by the Austrian Academy of Sciences and a post-graduate fellowship by the University of Innsbruck; L. Hörtnagl acknowledges financial support through a PhD fellowship by the University of Innsbruck. D. Gianelle and L. Vescovo are thanked for loaning of the portable spectroradiometer. Family Hofer (Neustift, Austria) and the Landeslehranstalt Rotholz, particularly H. Haas, are acknowledged for granting us access to the study sites. Long-term temperature and precipitation data have been generously provided by the Austrian Hydrographic Service.

Edited by: A. Arneth

\section{References}

Asner, G. P.: Biophysical and biochemical sources of variability in canopy reflectance, Remote Sens. Environ., 64, 234-253, 1998.

Aubinet, M., Grelle, A., Ibrom, A., Rannik, Ü., Moncrieff, J., Foken, T., Kowalski, A. S., Martin, P. H., Berbigier, P., Bernhofer, Ch., Clement, R., Elbers, J., Granier, A., Grünwald, T., Morgenstern, K., Pilegaard, K., Rebmann, C., Snijders, W., Velentini, R., and Vesala, T.: Estimates of the annual net carbon and water exchange of forests: The EUROFLUX methodology, Adv. Ecol. Res., 30, 113-175, 2000.

Bahn, M., Schmitt, M., Siegwolf, R., Richter, A., and Brüggemann, N.: Does photosynthesis affect grassland soil-respired $\mathrm{CO}_{2}$ and its carbon isotope composition on a diurnal timescale?, New Phytologist, 182, 451-460, 2009.
Baldocchi, D. D.:"Breathing" of the terrestrial biosphere: Lessons learned from a global network of carbon dioxide flux measurement systems, Aust. J. Bot., 56, 1-26, 2008.

Baldocchi, D. D., Falge, E., Gu, L., Olson, R., Hollinger, D., Running, S., Anthoni, P., Bernhofer, C., Davis, K., Fuentes, J., Goldstein, A., Katul, G., Law, B., Lee, X., Malhi, Y., Meyers, T., Munger, J. W., Oechel, W., Pilegaard, K., Schmid, H. P., Valentini, R., Verma, S., Vesala, T., Wilson, K., and Wofsy, S.: FLUXNET: a new tool to study the temporal and spatial variability of ecosystem-scale carbon dioxide, water vapor and energy flux densities, B. Am. Meteorol. Soc., 82, 2415-2435, 2001.

Baldocchi, D. D., Hicks, B. B., and Meyers, T. P.: Measuring biosphere-atmosphere exchanges of biologically related gases with micrometeorological methods, Ecology, 69, 1331-1340, 1988.

Canadell, J. G., Pataki, D. E., Gifford, R., Houghton, R. A., Luo, Y., Raupach, M. R., Smith, P., and Steffen, W.: Saturation of the terrestrial carbon sink, in: Terrestrial Ecosystems in a Changing World, edited by: Canadell, J. G., Pataki, D. E., and Pitelka L. F., Springer, Germany, 59-78, 2007.

Davidson, E. A. and Janssens, I. A.: Temperature sensitivity of soil carbon decomposition and feedbacks to climate change, Nature, 440, 165-173, 2006.

Falge, E., Baldocchi, D., Olson, R., Anthoni, P., Aubinet, M., Bernhofer, Ch., Burba, G., Ceulemans, R., Clement, R., Dolman, H., Granier, A., Gross, P., Grünwald, T., Hollinger, D., Jenson, N. -O., Katul, G., Keronen, P., Kowalski, A., Lai, C. T., Law, B., Meyers, T., Moncrieff, J., Moors, E. J., Munger, W., Pilegaard, K., Rannik, Ü ., Rebmann, C., Sukyer, A., Tenhunen, J., Tu, K., Verma, S., Vesala, T., Wilson, K., and Wofsy, S.: Gap filling strategies for defensible annual sums of net ecosystem exchange, Agr. Forest Meteorol., 107, 43-69, 2001.

Gamon, J. A., Peñuelas, J., and Field, C. B.: A narrow-waveband spectral index that tracks diurnal changes in photosynthetic efficiency, Remote Sens. Environ., 41, 35-44, 1992.

Gianelle, D., Vescovo, L., Marcolla, B., Manca, G., and Cescatti, A.: Ecosystem carbon fluxes and canopy spectral reflectance of a mountain meadow, Int. J. Remote Sens., 30, 435-449, 2009.

Goudriaan, J.: Crop Micrometeorology: A Simulation Study. Wageningen, Centre for Agricultural Publishing and Documentation, 1977.

Goudriaan, J. and van Laar, H. H.: Modelling potential crop growth processes, Kluwer Academic Publishers, Dordrecht, 1994.

Grace, J., Nichol, C., Disney, M., Lewis, P., Quaife, T., and Bowyer, P.: Can we measure terrestrial photosynthesis from space directly, using spectral reflectance and fluorescence?, Global Change Biol., 13, 1484-1487, 2007.

Hammerle, A., Haslwanter, A., Tappeiner, U., Cernusca, A., and Wohlfahrt, G.: Leaf area controls on energy partitioning of a temperate mountain grassland, Biogeosciences, 5, 421-431, 2008, http://www.biogeosciences.net/5/421/2008/.

Haslwanter, A., Hammerle, A., and Wohlfahrt G.: Open- vs. closedpath eddy covariance measurements of the net ecosystem carbon dioxide and water vapour exchange: a long-term perspective, Agr. Forest Meteorol., 149, 291-302, 2009.

Högberg, P., Nordgren, A., Buchmann, N., Taylor, A. F., Ekblad, A., Högberg, M. N., Nyberg, G., Ottoson-Lofvenius, M., and Read, D. J.: Large-scale forest girdling shows that current photosynthesis drives soil respiration, Nature, 411, 789-792, 2001. 
Huemmrich, K. F., Black, T. A., Jarvis, P. G., McCaughey, J. H., and Hall, F. G.: High temporal resolution NDVI phenology from micrometeorological radiation sensors, J. Geophys. Res., 104(D22), 27935-27944, 1999.

Jenkins, J. P., Richardson, A. D., Braswell, B. H., Ollinger, S. V., Hollinger, D. Y., and Smith, M.-L.: Refining light-use efficiency calculations for a deciduous forest canopy using simultaneous tower-based carbon flux and radiometric measurements, Agr. Forest Meteorol., 143, 64-79, 2007.

Larcher, W.: Ökophysiologie der Pflanzen, Eugen Ulmer, Stuttgart, 2001.

Liu, H. Q. and Huete, A. R.: A feedback based modification of the NDVI to minimize canopy background and atmospheric noise, IEEE T. Geosci Remote, 33, 457-465, 1995.

Louis, J., Ounis, A., Ducret, J. -M. Evain, S., Laurila, T., Thum, T., Aurela, M., Wingsle, G., Alonso, L., Pedros, R., and Moya, I.: Remote sensing of sunlight induced chlorophyll fluorescence and reflectance of Scots pine in the boreal forest during spring recovery, Remote Sens. Environ., 96, 37-48, 2005.

McMichael, C. E., Hope, A. S., Stow, D. A., Fleming, J. B., Vourlitis, G., and Oechel, W. C.: Estimating $\mathrm{CO}_{2}$ exchange at two sites in Arctic tundra ecosystems during the growing season using a spectral vegetation index, Int. J. Remote Sens., 20, 638-698, 1999.

Moffat, A. M., Papale, D., Reichstein, M., Hollinger, D. Y., Richardson, A. D., Barr, A. G., Beckstein, C., Braswell, B. H., Churkina, G., Desai, A. R., Falge, E., Gove, J. H., Heimann, M., Hui, D., Jarvis, A. J., Kattge, J., Noormets, A., and Stauch, V. J.: Comprehensive comparison of gap-filling techniques for eddy covariance net carbon fluxes, Agr. Forest Meteorol., 147, 209-232, 2007.

Malenovsky, Z., Mishra, K. B., Zemek, F., Rascher, U., Nebal, L.: Scientific and technical challenges in remote sensing of plant canopy reflectance and fluorescence, J. Exp. Botany, 60, 29873000, 2009.

Moya, I., Camenen, L., Evain, S., Goulas, Y., Cerovic, Z. G., Latouche, G., Flexas, J., and Ounis, A.: A new instrument for passive remote sensing 1. Measurements of sunlight-induced chlorophyll fluorescence, Remote Sens. Environ., 91, 186-197, 2004.

Olofsson, P., Lagergren, F., Lindroth, A., Lindstrm, J., Klemedtsson, L., Kutsch, W., and Eklundh, L.: Towards operational remote sensing of forest carbon balance across Northern Europe, Biogeosciences, 5, 817-832, 2008,

http://www.biogeosciences.net/5/817/2008/.

Reichstein, M., Falge, E., Baldocchi, D., Papale, D., Aubinet, M., Berbigier, P., Bernhofer, C., Buchmann, N., Gilmanov, T., Granier, A., Grünwald, T., Havránková, K., Ilvesniemi, H., Janous, D., Knohl, A., Laurela, T., Lohila, A., Loustau, D., Matteucci, G., Meyers, T., Miglietta, F., Ourcival, J. -M., Pumpanen, J., Rambal, S., Rotenberg, E., Sanz, M., Tenhunen, J., Seufert, G., Vaccari, F., Vesala, T., Yakir, D., and Valentini, R.: On the separation of net ecosystem exchange into assimilation and ecosystem respiration: review and improved algorithm, Global Change Biol., 11, 1424-1439, 2005.

Richardson, A. D. and Hollinger, D. Y.: A method to estimate the additional uncertainty in gap-filled NEE resulting from long gaps in the $\mathrm{CO}_{2}$ flux record, Agr. Forest Meteorol., 147, 199-208, 2007.
Richardson, A. D., Jenkins, J. P., Braswell, B. H., Hollinger, D. Y., Ollinger, S. V., and Smith, M.-L.: Use of digital webcam images to track spring green-up in a deciduous forest, Oecologia, 152, 323-334, 2007.

Rocha, A. V. and Shaver, G. R.: Advantages of a two band EVI calculated from solar and photosynthetically active radiation fluxes, Agr. For. Meteorol., 149, 1560-1563, 2009.

Rouse, J. W., Haas, R. H., Schell, J. A., and Deering, D. W.: Monitoring Vegetation Systems in the Great Plains with ERTS, in: Third ERTS Symposium, NASA SP-353, Vol. 1, 309-317, US Government Printing Office, Washington, DC, 1973.

Ruimy, A., Jarvis, P. G., Baldocchi, D. D., and Saugier, B.: $\mathrm{CO}_{2}$ fluxes over plant canopies and solar radiation: a review, Adv. Ecol. Res., 26, 1-68, 1995.

Running, S. W., Baldocchi, D. D., Turner, D. P., Gower, S. T., Bakwin, P. S., and Hibbard, K. A.: A global terrestrial monitoring network integrating tower fluxes, flask sampling, ecosystem modelling and EOS satellite data, Remote Sens. Environ., 70, 108-127, 1999.

Sims, D. A., Rahman, A. F., Cordova, V. D., Baldocchi, D. D., Flanagan, L. B., Goldstein, A. H., Hollinger, D. Y., Misson, L., Monson, R. K., Schmid, H. P., Wofsy, S. C., and Xu, L.: Midday values of gross CO 2 flux and light use efficiency during satellite overpasses can be used to directly estimate eight-day mean flux, Agr. Forest Meteorol., 131, 1-12, 2005.

Smith, E. L.: The influence of light and carbon dioxide on photosynthesis, J. Gen. Physio., 20, 807-830, 1937.

Solomon, S., Quin, D., Manning, M., Chen, Z., Marquis, M., Averyt, K. B., Tignor, M., and Miller, H. L.: Climate Change 2007: The Physical Science Basis. Contribution of Working Group I to the Fourth Assessment Report of the Intergovernmental Panel on Climate Change, Cambridge University Press, Cambridge, 2007.

Steffen, W., Noble, I., Canadell, J., Apps, M., Schulze, E. -D., Jarvis, P. G., Baldocchi, D., Ciais, P., Cramer, W., Ehleringer, J., Farquhar, G., Field, C. B., Ghazi, A., Gifford, R., Heimann, M., Houghton, R., Kabat, P., Körner, Ch., Lambin, E., Linder, S., Mooney, H. A., Murdiyarso, D., Post, W. M., Prentice, C., Raupach, M. R., Schimel, D. S., Shvidenko, A., and Valentini, R.: The terrestrial carbon cycle: implications for the Kyoto protocol, Science, 280, 1393-1394, 1998.

Turner, D. P., Guzy, M., Lefsky, M. A., Rits, W. D., Van Tuyl, S., and Law, B. E.: Monitoring forest carbon sequestration with remote sensing and carbon cycle modelling, Environ. Management, 33, 457-466, 2004.

van der Tol, C., Verhoef, W., Timmermans, J., Verhoef, A., and Su, Z.: An integrated model of soil-canopy spectral radiances, photosynthesis, fluorescence, temperature and energy balance, Biogeosciences, 6, 3109-3129, 2009, http://www.biogeosciences.net/6/3109/2009/.

Wang, Q., Tenhunen, J., Dinh, N. Q., Reichstein, M., Vesala, T., and Keronen, P.: Similarities in ground- and satellite-based NDVI time series and their relationship to physiological activity of a Scots pine forest in Finland, Remote Sens. Environ., 93, 225237, 2004.

Wang, Q., Tenhunen, J., and Vesala, T.: Gross primary production simulation in a coniferous forest using a daily gas exchange model with seasonal change of leaf physiological parameters derived from remote sensing data, Int. J. Remote Sens., 30, 30133025, 2009. 
Wilson, T. B. and Meyers, T. P.: Determining vegetation indices from solar and photosynthetically active radiation fluxes, Agr. Forest Meteorol., 144, 160-179, 2007.

Wohlfahrt, G., Sapinsky, S., Tappeiner, U., and Cernusca, A.: Estimation of plant area index of grasslands from measurements of canopy radiation profiles, Agr. Forest Meteorol., 109, 1-12, 2001.
Wohlfahrt, G., Hammerle, A., Haslwanter, A., Bahn, M., Tappeiner, U., Cernusca, A.: Seasonal and inter-annual variability of the net ecosystem $\mathrm{CO}_{2}$ exchange of a temperate mountain grassland: Effects of weather and management, J. Geophys. Res., 113, D08110, doi:10.1029/2007JD009286, 2008. 